\title{
Remote-Controlled Technology and Robot Technology for Accident Response and Decommissioning of Fukushima Nuclear Power Plant
}

The University of Tokyo, Hajime Asama

\begin{abstract}
In the aftermath of the accident that occurred at TEPCO's Fukushima Daiichi Nuclear Power Plant, robots and remote-controlled equipment had to be deployed to perform various tasks in a high-radiation environment. This commentary describes the robots and remote-controlled equipment deployed to date and explains ongoing technological developments for the decommissioning. It further discusses what measures should be taken in anticipation of the decommissioning of the Fukushima Nuclear Power Plant and any possible future disasters.
\end{abstract}

\section{Introduction}

In the aftermath of the accident that occurred at TEPCO's Fukushima Daiichi Nuclear Power Plant, robots and remote-controlled equipment had to be deployed to perform various tasks in a high-radiation environment ${ }^{1}$. Despite the difficulties involved in deploying such equipment immediately after the accident, more than 30 different types of robotic technologies have been employed so far, and they have made a significant contribution to performing the tasks required to respond to the accident and prepare for the decommissioning work. This commentary describes the robots and remote-controlled equipment deployed to date and explains ongoing technological developments for the decommissioning. It further discusses what types of technologies need to be developed in anticipation of the decommissioning of the Fukushima Nuclear Power Plant and what measures should be taken to prepare for any possible future accidents.

DOI : 10.15669/fukushimainsights.Vol.2.199

(c) 2021 Atomic Energy Society of Japan. All rights reserved.

Originally published in Journal of the Atomic Energy Society of Japan (ISSN 1882-2606), Vol. 56, No. 5, p. 313-317 (2014)

in Japanese. (Japanese version accepted: December 8, 2013) 


\section{Need for the Effective Application of Robotics in Response to the Accident at the Fukushima Daiichi Nuclear Power Plant}

In the initial response to the accident, robots and remote-controlled equipment were assigned to perform tasks such as assessing the conditions there, cooling and stabilizing the reactors and spent fuel pools, containing any contaminants, and removing debris to prepare a better working environment. Since the attainment of a cold shutdown in January 2012, robots and remote-controlled equipment have been assigned to remove fuel from the spent fuel pools and fuel debris to prepare for the decommissioning work. Nonetheless, their top priority remains to minimize the radiation exposure of workers who carry out various on-site tasks.

Immediately after the accident, the Japanese government and TEPCO set up six special project teams for handling the accident response and recovery efforts at the Fukushima Daiichi Nuclear Power Plant. One of these teams was the Remote Control Project Team, which was established to discuss how robots and remote-controlled equipment could be deployed on the site.

The government and TEPCO drew up a tentative roadmap for remedying the accident at the Fukushima Daiichi Plant, and emergency response activities were carried out accordingly. Immediately after the accident, robots and remote-controlled equipment had to be mobilized to perform a variety of tasks because the extremely high levels of radiation emitted by the contaminants released around the reactor buildings made it extremely difficult for workers to approach the site. During that initial phase, the emergency response was often quite chaotic. TEPCO, the user of this remote-controlled equipment, could not keep track of the characteristics and sources of the available robotic technologies. Meanwhile, the researchers and manufacturers involved in developing robots could not fully understand what types of solutions were required and where they would be applied. To address this problem, robotics researchers and engineers began exchanging information regarding the ongoing accident response and established the Robotics Taskforce for Anti-Disaster (ROBOTAD) ${ }^{2}$. In addition to collecting information on available robotic technologies, they conducted technical discussions both online and in person regarding the deployment of robots at disaster or accident sites. The topics that were discussed included the resistance of robot components to radiation and the possibility of employing wireless communication for the remote control of robots inside the reactor buildings. They also supported the Remote Control Project Team, which had been established by the Japanese government and TEPCO, through the provision of various kinds of information.

There was an extremely wide-ranging need for robotic solutions to be employed in the emergency response and decommissioning. Specific examples of these solutions included the following: cooling by water injection; surveys conducted both inside and outside buildings (image capturing as well as measuring of the radiation dose, temperature, humidity, and oxygen concentration); debris removal; transport and installation of equipment and materials; sampling of dust, contaminated water, and fuel debris; shielding; and decontamination. These assigned tasks also had to be carried out in a wide range of places with diverse environmental conditions. Many different types of robotic technologies have been employed to address this variety of requirements. 


\section{Effective Employment of Robotic Technologies in the Acci- dent Response}

\section{Cooling}

In the immediate aftermath of the accident at TEPCO's Fukushima Daiichi Nuclear Power Plant, the most pressing task was the cooling of reactors and spent fuel pools. At Unit 4, mobile concrete pumps manufactured by Sany Heavy Industry (China) and Putzmeister were deployed on March 22, 2011, to enable water to be safely injected. Other types of pumps were deployed at Units 1, 3, and 4 after a modification had been applied to facilitate remote control. These pumps were called by various pet names, such as elephant, giraffe, mammoth, and zebra. The boom (arm) of each mobile concrete pump was remotely controlled via wireless LAN by using a light and camera mounted on the tip of the boom to ensure that the water injection could be performed stably while the video captured by the camera was monitored in an anti-seismic building.

\section{Debris Removal}

On April 6, 2011, debris removal was initiated using unmanned construction machines. Immediately after the accident, the premises of the Fukushima Daiichi Nuclear Power Plant were full of debris from the tsunami and the hydrogen explosion that occurred at the reactor buildings. The debris produced by the hydrogen explosion had particularly high levels of radiation, which proved a considerable obstruction to recovery efforts at the site. A joint venture formed by Taisei Corporation, Kajima Corporation, and Shimizu Corporation deployed unmanned construction machines to remove the debris, thereby reducing the exposure dose for workers carrying out tasks in this high-radiation environment. These machines included backhoes, tracked dump trucks, operator vehicles, and camera vehicles.

Equipped with a grab, each unmanned backhoe was remotely controlled to load debris into containers. The unmanned tracked dump trucks were then remotely controlled to transport the containers to the storage site. The removal of debris using these unmanned construction machines continued for about seven months until November. As a result, about $20,000 \mathrm{~m}^{3}$ of debris (outdoor debris only) was removed from an area of about $56,000 \mathrm{~m}^{2}$.

After that, debris removal was initiated on May 10, 2011, using remote-controlled equipment both inside and outside of carry-in entrance for large equipment located at the reactor building for Unit 3. The equipment that was deployed included the Talon and Bob Cat, manufactured by QinetiQ (United States), and the Brokk-90 and Brokk-330, manufactured by Brokk (Sweden). This equipment was also employed to remove large amounts of highly radioactive debris from inside the reactor buildings that had experienced a hydrogen explosion. Debris removal was performed with the two Talon units directly provided by QinetiQ. Another Talon unit provided by the Idaho National Laboratory was deployed for other purpose. On July 25, 2013, the ASTACO-SoRa, manufactured by Hitachi Engineering \& Services, was deployed as a type of remote-controlled heavy machinery to remove debris and other obstacles from the ground floor of the reactor building for Unit 3.

Debris removal was performed remotely on the top floor of each reactor building that had experienced a hydrogen explosion. The debris in the reactor building for Unit 4 was removed by manned construction machines, since the radiation level was low. In contrast, debris was removed from the reactor building for Unit 3 remotely because of the high levels of radiation there. Unmanned cranes, backhoes (nibblers), and other heavy machinery were deployed on 
the ground and on the platform that had been built around the reactor building to reduce the exposure dose for workers.

On June 24, 2013, Kajima Corporation announced that complete automation had been achieved for the transportation of highly radioactive debris from Unit 3. This automated transportation is being performed by unmanned tracked dump trucks for a distance of about $1 \mathrm{~km}$ from the debris removal site in the reactor building to the on-site storage facility. Round trips from the storage facility to the storage site, which include a slope with a gradient of $7 \%$ and a K-turn and cover a distance of around $800 \mathrm{~m}$, are carried out by unmanned folk lifts.

\section{Surveys}

On April 17, 2011, a survey was initiated inside the reactor buildings by using two PackBot units, manufactured by iRobot (United States). Initially, these robots were used to measure the radiation dose, ambient temperature, ambient humidity, and oxygen concentration. Since then, the PackBots have been deployed many times to perform various other tasks, such as checking the integrity of the core spray systems and surveying the ground floor of the reactor buildings.

In June 2011, the Quince was deployed extensively in missions that required moving up and down stairs inside buildings. Capable of crossing over debris and other obstacles, this robot was developed by organizations including the Chiba Institute of Technology, Tohoku University, the International Rescue System (IRS), and the New Energy and Industrial Technology Development Organization (NEDO). The Quince failed to accomplish its mission to sample contaminated water in the basement and install a water level indicator on June 24, 2011. However, it made a remarkable contribution to a survey conducted of the third floor of Unit 2 on July 8, 2011. It was also deployed effectively along with the PackBot to check a core spray system on July 22, 2011. On October 20, 2011, it successfully completed a survey on the fifth floor of Unit 2. However, communication problems caused it to become inoperative on the third floor while it was returning from its mission. Later, the Quince 2 and the Quince 3, which are the same type of model, were deployed. These robots are effective in conducting indoor surveys, such as the one conducted for the main steam isolation valve (MSIV) room on the ground floor of the reactor building for Unit 2.

Other robots and equipment such as the following were also deployed to conduct various surveys in reactor buildings that cannot be easily accessed by workers: the JAEA-3, a survey robot developed by the Japan Atomic Energy Agency (JAEA); the Survey Runner, developed by Topy Industries; the FRIGO-MA, developed by Mitsubishi Electric TOKKI Systems; a robot developed by Honda and AIST for surveying elevated spots; and a quadrupedal robot and a small vehicle developed by Toshiba.

In addition to the deployment of these robots and remote-controlled equipment, robotic solutions such as the following have also been employed to conduct various surveys: the T-Hawk, a small-scale unmanned helicopter manufactured by Honeywell (United States), conducted an aerial survey of the reactor buildings; an industrial fiberscope was deployed in a survey conducted inside the primary containment vessel for Unit 2; the ROV, an underwater robot manufactured by Hitachi, surveyed the inside of the spent fuel pool for Unit 4 and drew a debris distribution map; a balloon manufactured by Hitachi was employed in a survey of the operation floor for Unit 1; the RC-1, a robot-operated vehicle manufactured by the JAEA, was deployed in a survey conducted together with the Talon, a robot manufactured by QinetiQ (United States); and measurements of the dose distribution were taken using a gamma camera. 
On November 13, 2013, an underwater survey robot developed in a project (described later) conducted by the Agency for Natural Resources and Energy (ANRE) identified contaminated water leaking from the primary containment vessel into the torus room. This robot was developed by Hitachi-GE Nuclear Energy based on discussions held by the Remote Control Task Force and more detailed discussions held by one of its working groups headed by Professor Tamaki Ura, who works at the Kyushu Institute of Technology. Many other robots had been deployed earlier to locate contaminated water leaks, but this first discovery of a leak by a robot is worth mentioning.

\section{Decontamination}

From the end of June to the beginning of July in 2011, the Warrior and PackBot, manufactured by iRobot (United States), were deployed to clean the reactor building for Unit 3. A cleaning system was mounted on the Warrior in an attempt to clean and decontaminate the floor surface and reduce the ambient dose rate, but this had little effect. However, the Warrior is still used to move obstacles in the reactor building for Unit 3.

Since November 28, 2013, the decontamination of the ground floor in the reactor building for Unit 2 has been conducted through the remote operation of a decontamination system developed by ATOX. Various other solutions have gradually been introduced as well, including a scabbler manufactured by Pentek as well as a high-pressure washing unit, dry-ice blasting unit, and blast and vacuum recovery unit developed with grants awarded by ANRE (described later).

\section{Development of Robotic Technologies for Decommissioning}

The Japan Atomic Energy Commission's Special Committee on Mid-and-Long-Term Measures for TEPCO's Fukushima Daiichi Nuclear Power Plant discussed how to overcome these extremely difficult challenges to achieve their mission ${ }^{3)}$. They presented Mid-and-Long-Term Roadmap towards the Decommissioning ${ }^{4)}$ together with the following two tasks related to research and development in preparation for the decommissioning work.

- The Japanese government is to pursue the necessary research and development responsibly.

- The accident is to be brought under control over the mid- to long-term with assembling domestic and international wisdom.

Accordingly, the Japanese government and TEPCO established the Research and Development Task Force for the Conference on Mid-and-Long-Term Measures as well as a steering committee for managing the progress made in accordance with the Mid-and-Long-Term Roadmap. Both of these bodies conduct research and development for the Mid-and-LongTerm measures. In February 2013, the abovementioned conference was discontinued to reinforce the support mechanism for the decommissioning of TEPCO's Fukushima Daiichi Nuclear Power Plant. Instead, the Council for the Decommissioning of TEPCO's Fukushima Daiichi Nuclear Power Plant was established. A detailed verification of the progress made in preparation for the decommissioning work is being conducted by a secretariat conference of the Advisory Committee for Decommissioning (meetings by the teams presently in charge of decommissioning and implementing measures for contaminated water). 
Meanwhile, in August 2013, the International Research Institute for Nuclear Decommissioning (IRID) was established as an association for conducting research and development related to decommissioning technologies by bringing together knowledge from Japan and overseas. This institute will take the lead in such research and development going forward.

The following sections present examples of the research and development related to robots and remote-controlled equipment that has been conducted to date in preparation for the decommissioning work.

\section{Research and Development Related to Remote-Controlled Equipment That Has Been Subsidized or Commissioned by the ANRE}

In FY2012, three nuclear power plant manufacturers (Hitachi-GE Nuclear Energy, Toshiba, and Mitsubishi Heavy Industries) conducted research and development for projects that were subsidized or commissioned by ANRE under Japan's Ministry of Economy, Trade and Industry (METI). Grants of 500 million yen were allocated for the development of technologies to be used in responding to accidents at commercial nuclear power reactors. Another 1.5 billion yen was commissioned for infrastructure improvements. These research and development activities included the decontamination of inside reactor buildings, the conducting of surveys on leaks from reactor buildings and primary containment vessels, the conducting of surveys inside primary containment vessels, the plugging of leaks at reactor buildings, the conducting of repairs to the bottom of primary containment vessels, and the conducting of long-term assessments to validate the integrity of pressure vessels and primary containment vessels in relation to corrosion.

These three plant manufacturers issued calls for proposals to study applicable technologies required for the development of these technologies by bringing together insights from Japan and overseas, which were then compiled in a technology catalog ${ }^{5)}$. According to this catalog, a call for proposals was issued for each type of technology to be developed to incorporate useful technologies from Japan and overseas.

In FY2013, ANRE allocated a budget for subsidizing development projects and commissioning the decommissioning of commercial power reactors and improving the safety infrastructure. Work on the development of the following technologies is underway: technologies for identifying and repairing leaks from primary containment vessels, technologies for examining the inside of primary containment vessels, technologies for remote-controlled decontamination, technologies for examining the inside of pressure vessels, and technologies for containing, transporting and storing fuel debris.

\section{Remote Control Task Force}

The abovementioned Research and Development Task Force for the Conference on Midand-Long-Term Measures, which was established by the Japanese government and TEPCO, conducted individual projects for the respective R\&D missions. Taking into account the many challenges that are expected in relation to the development of robots and remote-controlled equipment, the Remote Control Task Force was established as a cross-sectional unit that would cover all projects. This unit is assigned to examine how robot technologies should be applied to address the various needs and achieve the respective missions, propose solutions, propose backup plans in case an approach fails, establish specific R\&D projects, and provide advice on the implementation of these projects.

In addition to the development of equipment as mentioned earlier, working groups were 
established to accomplish the respective missions and discuss the remote control systems to be deployed. These missions include the conducting of surveys of the rooftops of reactor buildings, the conducting of surveys of leaks from suppression chambers, and the measurement of water levels in suppression chambers. More specifically, these working groups are investigating the use of various measurement methods and survey systems that employ small airships, small unmanned helicopters, suspension mechanisms, and underwater survey robots. In FY2012, for instance, a working group led by Professor Matsuhira of the Shibaura Institute of Technology developed a remote-controlled device for measuring the water level inside a suspension chamber through the development of basic technologies for the remote-controlled measurement of the water level in a cylindrical container under a project for developing a technological platform for responding to accidents at commercial reactors that was conducted by ANRE under METI. In addition, a remote-controlled underwater survey robot was developed during the technological development of underwater survey robots for the advancement of a technological platform for remote-controlled operations. These inventions have already been deployed, and they have produced remarkable outcomes.

Another working group led by Professor Yoneda of the Chiba Institute of Technology was established under the Remote Control Task Force when a quadrupedal robot encountered some trouble during a survey around the bottom part of the venting pipes in a suppression chamber. The working group examined the problem and proposed a modification. Subsequently, appropriate measures were implemented based on this examination and the survey around the bottom part of the venting pipes was successfully completed.

The development of robots and remote-controlled equipment needs to be continued by the Advisory Committee for Decommissioning after the task has been carried over from the Research and Development Task Force for the Conference on Mid-and-Long-Term Measures, which was established by the Japanese government and TEPCO. The role of the Remote Control Task Force is expected to be continued by the IRID, which was, as mentioned earlier, established as an association for conducting research and development related to decommissioning technologies.

\section{Project for Unmanned Disaster Response Systems}

NEDO implemented a third supplemental budget of 1 billion yen for an unmanned disaster response system project ${ }^{6}$ in FY2011 to develop common platforms for disaster responses. This project was implemented due to the perceived need for practical robots (unmanned systems) that can respond to disasters in Japan. Working and traveling mechanisms are being developed to carry out unmanned monitoring operations by approaching environments that contain hazardous contaminants in spaces that are too small or difficult for workers to access.

The items being developed are as follows.

(1) Development of working and traveling mechanisms

[1] Development of small remote-controlled travel units with an excellent obstacle crossing capacity

[2] Development of communication technologies

[3] Development of remote-controlled human interfaces

[4] Development of remote-controlled wheeled platforms for loading and handling heavy objects in small spaces

[5] Development of remote-controlled handling platforms for loading heavy objects 
(2) Development of underlying technologies for measurements and work

[6] Development and improvement of devices for monitoring and handling operations in the air and underwater

(a) Development of gamma cameras

(b) Development of contamination mapping technologies

(c) Development of training simulators for robot operations conducted during disaster responses

(d) Development of amphibian traveling units

(3) Development of assistant robots for disaster responses

[7] Development of assistant robots

This project has not been undertaken as part of efforts to respond to nuclear accidents, but the technologies being developed under this project are deemed applicable to the Mid-andLong-Term Measures being taken in response to the Fukushima Nuclear Accident. There are high expectations that these technologies will be deployed extensively in preparation for the decommissioning work.

\section{Future Tasks}

\section{Preparations for Decommissioning}

In November 2013, the removal of fuel from spent fuel pools marked the beginning of Phase 2 under the Mid-and-Long-Term Roadmap. However, the decommissioning work is expected to take about 30 to 40 years, and it will require the completion of a series of tasks that cannot be performed easily by workers, such as the conducting of decontamination work, the identification and repair of contaminated water leaks, and the conducting of surveys and removal of fuel debris. Consequently, robots and remote-controlled equipment must be continuously developed in preparation for the decommissioning work. According to the current roadmap, the removal of fuel debris is scheduled to take place after the primary containment vessels have been repaired and shielded with water. In practice, however, the performance of integrity checks and the conducting of repairs so that the vessels can be filled with water is expected to prove extremely difficult. As a backup, it may be necessary to develop technologies for removing fuel debris from the air. In that event, the necessary equipment will be need to have a high level of resistance against radiation, so robust base technologies must be developed.

All of the robots and remote-controlled equipment required for the decommissioning work will need to be developed from scratch. Even after the research and development has been completed, the robots and remote-controlled equipment will need to be sufficiently sophisticated to be able to perform their roles reliably. They will also need to be deployed only after due verification of their functions, demonstration tests, and operator training. Having established the Fukushima Nuclear Plant Decommissioning Safety Research Establishment, the JAEA is carrying out its plan to construct and operate a facility to demonstrate remote-controlled equipment and devices (known as a "mockup facility"). This facility will play a crucial role in function verification, demonstration tests, and operator training. 


\section{Preparations for a Nuclear Emergency}

Germany and France have respectively established the KHG (1977) and Groupe INTRA (1988) as organizations for responding to a nuclear emergency. Both of these organizations maintain robots and other equipment to facilitate a practical response to a nuclear emergency by regularly trained operators. They are able to deploy the necessary equipment and personnel to any nuclear accident site within 24 hours. In Japan, the Fukushima Nuclear Accident has renewed the nation's awareness on the extreme importance of making preparations for any possible nuclear emergencies.

The Federation of Electric Power Companies of Japan (FEPC) intends to set up Nuclear Emergency Support Team in FY2015 in accordance with its goal of establishing a support mechanism for responding effectively to nuclear accidents through a diverse range and high level of measures. Furthermore, the Japan Atomic Power Company established the Nuclear Emergency Support Center and began to procure disaster response robots and conduct training program for the operators. The center plans to build up its capacity by procuring, deploying, and operating various types of robots so that it can respond to a wide range of disasters that require different kinds of operations under complex environments.

\section{Robots for Disaster Preparedness}

Japan is prone to a wide range of natural disasters, including earthquakes, tsunamis, typhoons, and volcanic eruptions. In addition, the country is experiencing a surging number of accidents associated with a deterioration of its social infrastructure (e.g., tunnels, bridges, expressways, and dams) and its industrial infrastructure (e.g., chemical plants and industrial complexes).

Since FY2011, the Council of Competitiveness-Nippon has been conducting projects related to disaster response robots. The council has been developing robotic technologies for responding to disasters and exploring measures for building their operation systems. They have also compiled recommendations related to applying these technologies to hone the industrial competitiveness of Japan ${ }^{7-9}$. Due to space limitations, detailed recommendations will be presented in a different report ${ }^{10)}$. Aside from the necessary research, development, and demonstration tests, the key point in maintaining robots for emergency preparedness is to ensure their regular use.

The Fukushima Nuclear Accident has presented us with the long-lasting task of decommissioning through the development and application of robotic technologies. These technologies are expected to drive the practical application of disaster response robots in society.

\section{Conclusions}

This commentary describes the various types of robots and remote-controlled equipment that have been deployed so far to respond to the accident at TEPCO's Fukushima Daiichi Nuclear Power Plant. It explains the technologies that need to be developed and applied in preparation for the decommissioning as well as in preparation for any future nuclear accidents. This commentary owes its insights to information related to the on-site deployment of robots and remote-controlled equipment that has been provided by Mr. Shin Yoshino and Mr. Tsutomu Tanaka from TEPCO and Mr. Shinji Kawatsuma from the JAEA.

The experience of Fukushima teaches us that we need to be prepared to mobilize robots 
and remote-controlled equipment to perform tasks that cannot be performed safely or easily by workers in response to a nuclear emergency, natural disaster, or any other man-made (industrial) disaster involving social and industrial infrastructure. This preparedness is vital for building national resilience.

\section{References}

1) Hajime Asama: Robotic Technologies Applied in Response to the Great East Japan Earthquake and Accidents at Nuclear Power Plants [in Japanese], ITU Journal, Vol. 42, No. 2, pp. 44-47, 2012.

2) http://roboticstaskforce.wordpress.com/.

3) Japan Atomic Energy Commission: Results of Discussions on Mid-and-Long-Term Measures at TEPCO's Fukushima Daiichi Nuclear Power Plant [in Japanese], Special Committee on Midand-Long-Term Measures at TEPCO's Fukushima Daiichi Nuclear Power Plant, 2011.

4) http://www.tepco.co.jp/nu/fukushima-np/roadmap/conference-j.html.

5) http://www.meti.go.jp/earthquake/nuclear/20120626_01.html.

6) http://www.nedo.go.jp/activities/ZZJP_100045.html.

7) http://www.cocn.jp/common/pdf/thema39-L.pdf.

8) http://www.cocn.jp/common/pdf/thema50-L.pdf.

9) http://www.cocn.jp/common/pdf/thema60-S.pdf.

10) Hajime Asama: R\&D for Practical Robot Technology and Establishment of Its Operation System for Disaster Response [in Japanese], Journal of the Robotics Society of Japan, Vol. 32, No. 1, pp. 37-41 (2014). 